\title{
Keinginan Berpindah Kerja ditinjau dari Persepsi Dukungan Organisasi Karyawan Toko Matahari Medan Fair
}

\section{Turnover Intention the role of Perceived Organizational Support Employee Matahari Medan Fair Store}

\author{
Menanti Lase*, Yulinda Septiani Manurung \& Mukhaira El Akmal \\ Fakultas Psikologi, Universitas Prima Indonesia, Indonesia
}

Diterima: 08 Februari 2020; Disetujui: 09 Maret 2020; Dipublish: 23 Maret 2020

* Coresponding Email: menantilase@gmail.com

\begin{abstract}
Abstrak
Tujuan penelitian ini adalah untuk mengetahui hubungan persepsi dukungan organisasi dengan keinginan berpindah kerja. Penelitian dilakukan dengan jumlah responden sebanyak 119 orang karyawan toko Matahari Medan Fair dipilih dengan menggunakan metode purposive sampling. Sebagai pendekatan masalah ini, digunakan acuan teori Azwar dan Arikunto. Data diperoleh dari skala pengukur dukungan organisasi dan keinginan berpindah kerja. Perhitungan dilakukan dengan uji asumsi, terdiri atas uji normalitas dan linieritas hubungan. Data dianalisis dengan korelasi product moment dengan SPSS 19 untuk Windows. Hasil analisis data yang didapat menunjukkan koefisien korelasi $-0,509$ dengan $\mathrm{p} 0,000(\mathrm{p}<0,05)$, hal ini membuktikan adanya hubungan negatif antara persepsi dukungan organisasi dan keinginan berpindah kerja. Persepsi dukungan organisasi adalah salah satu faktor yang dapat mempengaruhi niat berpindah dengan kontribusi $\left(\mathrm{R}^{2}\right)$ sebesar 25,9 persen dan sisanya sebesar 74,1 persen dipengaruhi oleh faktor lain yang tidak diteliti. Kesimpulannya, hipotesis adanya hubungan yang bersifat negatif antara persepsi dukungan organisasi dan keinginan berpindah kerja diterima.
\end{abstract}

Kata Kunci : Keinginan Berpindah Kerja, Persepsi Dukungan Organisasi

\begin{abstract}
Abstrack
The study was conducted to determine the effect of perceived organizational support to turnover intention. Research conducted by a number of renpondents 119 people employees at Matahari Medan Fair Store chosen by using purposive sampling method. as an approach to this problem the theoretical references by Azwar and Arikunto. Data are obtained from a scale to measure perceived organizational support and turnover intention. The calculation is performed by assumption test, consists of normality and consists linearity test of the relationship. The data are analyzed using Product Moment Correlation SPSS 19 for Windows. Results of the data analysis show a coefficient correlation of -0.509 with $p 0.000(p<$ 0.05), it shows there is a negative relationship between perceived organizational support and turnover intention. perceived organizational support is one of the factors affecting turnover intention with the contribution $\left(R^{2}\right)$ by 25,9 percent and the remaining of 74,1 percent is affected by other factors not examined. In conclusion, the hypothesis of there is a negative relationship between variable perceived organizational support and variable turnover intention is accepted. Keyword: Turnover Intention, Perceived Organizational Support.
\end{abstract}

How to Cite: Lase, M. Manurung, Y.S. \& Akmal, M.E. (2020). Keinginan Berpindah Kerja ditinjau dari Persepsi Dukungan Organisasi Karyawan Toko Matahari Medan Fair. Journal of Education, Humaniora and Social Sciences (JEHSS): 2(3):597 - 606 


\section{PENDAHULUAN}

Kekuatan utama dalam pekerjaan adalah kekuatan sumber daya manusia atau karyawan. Karyawan merupakan aset perusahaan dan pelaku utama produksi serta pemasaran hasil. Tidak mungkin strategi bisnis atau tujuan perusahaan tercapai jika tidak ada pelaku atau pekerjanya, dengan demikian karyawan menjadi pusat perhatian perusahaan dan berbagai pihak.

Namun pada kenyataannya banyak perusahaan yang kesulitan dalam menangani berbagai masalah atau kendala dalam mengelola sumber daya manusia atau karyawan. Mengelola sumber daya manusia sebagai aset yang berharga, untuk dijaga dan dilatih, kini jauh lebih penting dari sebelumnya.

Manajemen sumber daya manusia menjadi sangat penting bagi semua manajer, dari beberapa contoh, salah satunya adalah dimana pada saat mengelola pegawai, setiap manajer tidak ingin membuat kesalahan seperti membuat tingginya turnover intention karyawan.

Tingkat turnover intention yang tinggi dapat merugikan perusahaan, yaitu dari segi biaya rekruitmen, sumber daya, waktu maupun motivasi karyawan. Dengan tingginya tingkat turnover intention maka perusahaan harus mengeluarkan banyak biaya, diantaranya adalah pasangon karyawan yang hendak berpindah kerja, biaya merekrut karyawan baru serta biaya pelatihan dan training karyawan baru.

Faktor yang dapat mempengaruhi turnover intention salah satunya adalah perceived organizational support. Menurut Anshori dan Wangi (2017), dalam penelitianya terhadap karyawan PT. Leading Garment Industries Bandung, menyatakan bahwa perceived organizational support berpengaruh signifikan terhadap variabel turnover intention. Hasil ini menunjukkan bahwa dukungan organisasi memiliki pengaruh terhadap variabel keinginan berpindah kerja karyawan. Menurut Kim, dkk., (2011), turnover intention adalah aksi karyawan dalam meninggalkan organisasi dengan adanya keinginan dari dirinya untuk berpindah dengan Organisasi atau perusahaan yang lain.

Menurut Abdullah, dkk., (dalam Radzi, dkk., 2015), turnover didefinisikan sebagai pergerakan manusia masuk dan keluar dari pekerjaannya dalam suatu perusahaan. Menurut Wong (2012), intention adalah tentang alasan alasan yang mendasari mengapa perlu melakukan sesuatu, atau sebaliknya tetap diam dan tidak melakukan apa-apa. 
Menurut Supriyanto (dalam Ridlo, 2012) turnover intention merupakan proporsi dari jumlah anggota organisasi secara sukarela atau voluntary dan tidak secara sukarela atau non voluntary yang berniat meninggalkan organisasi dengan waktu tertentu. Turnover intention yaitu berfokus pada karyawan yang berencana, berniat, atau keinginan untuk meninggalkan organisasi secara suka rela (Jansen dan Rodt, 2015).

Ajzen (2005), dalam teori Planned Behavior menyampaikan ada tiga aspek turnover intention, yaitu : 1) Attitude toward the intention turnover (sikap pribadi) merupakan keinginan untuk melakukan maupun tidak melakukan tindakan turnover intention dengan keyakinan positif yang berasal dari dalam diri yang tindak melakukan turnover intention ; 2) Subjective norm (norma subyektif) merupakan dorongan atau pikiran untuk melakukan maupun tidak melakukan tindakan turnover intention yang dipengaruhi oleh aturan atau norma dalam pekerjaan. Turnover intention ini masih sebatas niatan individu dalam meninggalkan tempat kerja atau organisasi, dalam hal ini masih belum tahapan realisasi lingkungan social yang berpengaruh maupun berupa tekanan ; 3) Perceived behavioral control (kontrol perilaku) terdiri dari aspek, internal maupun eksternal. Aspek Internal di antaranya ketrampilan, kemampuan individu untuk melaksanakan tindakanya, serta informasi yang diperoleh, sedangkan aspek eksternal merupakan hal yang menghalangi individu dalam melakukan kegiatan, di antaranya ketergantungan individu terhadap orang lain serta kesempatan yang ada.

Adapun faktor-faktor yang mempengaruhi turnover intention antara lain:

1. Perceived organizational support. Putra dan Suana (2016), menyatakan bahwa terdapat pengaruh negatif dan signifikan antara perceived organizational support dengan turnover intention, hal ini membuktikan bahwa dukungan organisasi berpengaruh terhadap keinginan karyawan berpindah kerja.

2. Kepuasan kerja, Susilo, dkk, (2015) menyatakan bahwa adanya hubungan antara kepuasan kerja dengan tingkat turnover intention, karyawan yang merasa puas dengan hasil yang diperoleh akan menurunkan keinginan atau niat untuk berpindah kerja.

3. Kompensasi, Sugiati dan Khaidir (2016) menyatakan bahwa adanya pengaruh positif dan signifikan antara kompensasi dengan turnover intention. Artinya semakin tinggi nilai kompensasi yang diperoleh karyawan, maka semakin rendah tingkat turnover, 
Menanti Lase, Yulinda Septiani Manurung \& Mukhaira El Akmal. Keinginan Berpindah Kerja ditinjau

sebaliknya apabila nilai kompensasi semakin rendah maka turnover intention semakin tinggi.

4. Komitmen organisasi, Bitha dan Ardana (2017), menyatakan bahwa komitmen organisasi mempunyai hubungan dengan turnover intention, semakin tinggi nilai komitmen organisasi, maka semakin rendah turnover intention, sebaliknya apabila nilai komitmen organisasi semakin rendah maka tingkat turnover intention semakin tinggi.

5. Leadership capability, Kevin (2017), menyatakan bahwa leadership capability memiliki pengaruhterhadap turnover intention, Semakin tinggi nilai leadership capability, semakin rendah turnover intention, sebaliknya apabila nilai leadership capability semakin rendah maka tingkat turnover intention semakin tinggi.

6. Konflik kerja-keluarga, Nanda dan Utama (2015) menyatakan Semakin tinggi nilai konflik kerja-keluarga yang dialami karyawan maka semakin tinggi tingkat turnover intention, sebaliknya.

7. Motivasi kerja, Rahmasari (2017) menyatakan bahwa semakin tinggi nilai motivasi kerja yang dialami karyawan maka semakin rendah niat berpindah kerja karyawan, dan sebaliknya semakin rendah nilai motivasi kerja maka semakin tinggi tingkat turnover.

8. Role ambiguity. Sulistyawati, dkk., (2014), menyatakan bahwa role ambiguity berpengaruh signifikan dengan keinginan berpindah kerja. Menunjukkan bahwa ketidakjelasan peran yang terjadi membuat karyawan memiliki keinginan untuk berpindah kerja.

9. Perceived organizational support adalah dimana karyawan menerima atau merasa dihargai (misalnya, kenaikan gaji, peluang pelatihan pengembangan) dengan demikian merasa berkewajiban (norma timbal balik) untuk membantu organisasi atau perusahaan mencapai tujuannya melalui perilaku peningkatan peran kinerja atau ekstra peran (Hober, dkk., 2016).

Menurut Ismaidar (2015), perceived organizational support adalah penilaian karyawan mengenai seberapa jauh organisasi memberi nilai konstribusi, memberi dukungan, serta peduli terhadap kesejahteraan mereka. Jika karyawan beranggapan dukungan organisasi yang ia terima tinggi, maka karyawan tersebut mengakui atau

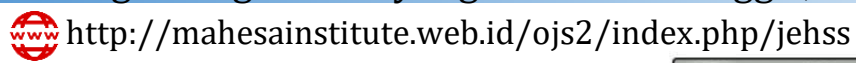

mmahesainstitut@gmail.com 600

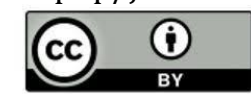

This work is licensed under a Creative Commons Attribution 4.0 
menyatukan identitas keanggotaan dalam organisasi dan mengembangkan hubungan serta persepsi yang bersifat positif dalam organisasi tersebut.

Suryani dan Hendryadi (2016), memberikan definisi secara konseptual dan definisi secara operasional. Secara konseptual perceived organizational support merupakan tingkat sejauhmana karyawan meyakini bahwa organisasi menghargai konstribusi mereka dan memiliki kepedulian dengan mereka. Definisi Secara operasional, perceived organizational support merupakan bagaimana perasaan karyawan mengenai penghargaan yang diperoleh dari organisasi meliputi dukungan pada pengembangan karir, pengembangan kemampuan, dan kesejahteraan.

Berdasarkan latar belakang yang telah dijelaskan, serta semakin banyaknya kasus turnover intention yang terjadi karena adanya karyawan yang merasa kurang didukungan oleh organisasi, maka peneliti tertarik untuk mengadakan penelitian dengan judul "Keinginan Berpindah Kerja Ditinjau Dari Persepsi Dukungan Organisasi Pada Karyawan PT. Matahari Department Store 261 Medan".

\section{METODE PENELITIAN}

Populasi pelaksanaan penelitian ini adalah karyawan PT. Matahari department store 261 Plaza Medan Fair yang berjumlah kurang lebih sebanyak 119 orang. Pemilihan lokasi penelitian atas dasar pertimbangan turnover intention dengan melihat data yang telah diperoleh sehingga muncul keinginan untuk mengetahui masalah-masalah yang timbul dalam perusahaan tersebut.

Pemilihan sampel menggunakan metode purposive sampling, dengan pertimbangan atau kriteria-kriteria tertentu, yaitu karyawan yang sudah bekerja di atas satu tahun dan merupakan karyawan tetap dalam perusahaan.

Pengumpulan data menggunakan pembagian skala, yaitu skala turnover intention dan perceived organizational support, skala disusun dalam bentuk pernyataan dengan menggunakan skala Likert, Skala Likert disusun dalam bentuk pernyataan bersifat favourable dan unfavorable, yang terdiri dari empat alternatif jawaban untuk setiap butir pernyataan. 
Menanti Lase, Yulinda Septiani Manurung \& Mukhaira El Akmal. Keinginan Berpindah Kerja ditinjau

Analisis data yang digunakan adalah korelasi Product Moment SPSS 19 for windows untuk mengetahui bagaimana hubungan antara variabel perceived organizational support dengan variabel turnover intention.

\section{HASIL DAN PEMBAHASAN}

Langkah awal yang dilakukan adalah analisis product moment, data yang telah diperoleh terlebih dahulu ditentukan nilai normalitas sebaran dan linieritas hubungan. Hasil uji normalitas dan hasil uji linieritas yang diperoleh memenuhi asumsi tersebut. Hasilnya dapat diliat pada tabel 1 dan tabel 2 berikut ini:

Tabel 1. Hasil Uji Normalitas

\begin{tabular}{cccccc}
\hline Variabel & SD & KS-Z & Sig. & P & Ket. \\
\hline Turnover intention & 11.731 & 1.039 & 0,231 & $>0.05$ & Sebaran normal \\
Perceived organizational support & 10.253 & 0.484 & 0,973 & $>0.05$ & Sebaran normal \\
\hline
\end{tabular}

Sumber : Analisis data Product Moment SPSS 19 for windows

Uji normalitas sebaran menggunakan uji Kolmogorov Smirnov Test. Data dapat dikatakan berdistribusi normal apabila $\mathrm{p}>0.05$ (Priyatno, 2010). Uji normalitas terhadap variabel ini turnover intention, diperoleh koefisien KS - Z = 1,039 dengan Sig sebesar 0.231 untuk uji 2 (dua) arah dan 0,519 untuk uji 1 (satu) arah (p > 0.05), yang berarti bahwa data pada variabel turnover intention memiliki sebaran atau berdistribusi normal. Uji normalitas pada variabel perceiced organizational support diperoleh koefisien KS-Z = 0,484 dengan Sig sebesar 0.973 untuk uji 2 (dua) arah dan 0,242 untuk uji 1 (satu) arah ( $\mathrm{p}>0.05$ ), yang berarti data variabel perceiced organizational support memiliki sebaran normal dan berdistribusi normal.

Tabel 2. Hasil Uji Linearitas Hubungan

\begin{tabular}{llll}
\hline Variabel & F & Sig & Keterangan \\
\hline Turnover intention & 57.700 & 0.000 & Linear \\
Perceived organizational support & & & \\
\hline
\end{tabular}

Sumber : Analisis data Product Moment SPSS 19 for windows

Berdasarkan tabel 2 dapat dikatakan bahwa variable turnover intention dan perceived organizational support mempunyai hubungan linear. Hal ini dapat dilihat dari nilai signifikan yaitu 0.000 maka $\mathrm{p}<0.05$, disimpulkan bahwa kedua variabel memiliki hubungan linear dan memenuhi syarat untuk melakukan analisa korelasi Product Moment. 
Hipotesis dalam penelitian ini berbunyi bahwa ada hubungan perceived organizational support dengan turnover intention: ada hubungan negatif yang signifikan antara perceived organizational support dengan turnover intention pada karyawan.

Diasumsikan bahwa semakin tinggi perceived organizational support yang diterima oleh karyawan, maka turnover intention semakin rendah, atau sebaliknya, semakin rendah perceived organizational support yang diterima oleh karyawan, maka turnover intention semakin tinggi.

Tabel 3. Korelasi Antara Perceived Organizational Support dengan Turnover Intention

\begin{tabular}{lcc}
\hline Analisis & Pearson Correlation & Signifikansi (p) \\
\hline Korelasi & -509 & 0.000 \\
\hline & Sumber : Analisis data Product Moment SPSS 19 for windows
\end{tabular}

Berdasarkan hasil analisis korelasi antara perceived organizational support dengan turnover intention, diperoleh koefisien korelasi product moment sebesar -0,509 dengan sig sebesar 0.000 ( $\mathrm{p}<0.05$ ). Hal ini menunjukkan bahwa adanya korelasi negatif perceived organizational support dengan turnover intention sehingga dikategorikan dengan hubungan yang cukup kuat (Priyatno, 2010).

Dari hasil perhitungan tersebut, maka hipotesis yang diajukan dalam penelitian ini menunjukkan ada hubungan negatif antara perceived organizational support dengan turnover intention diterima, dan dapat dinyatakan bahwa ada hubungan negatif antara perceived organizational support dengan turnover intention.

Hasil penelitian terhadap 119 karyawan PT. Matahari Department Store yang menjadi subjek penelitian, diperoleh hasil bahwa ada hubungan antara variabel perceived organizational support dengan turnover intention dengan koefisien korelasi Product Moment sebesar $\mathrm{r}=-0,509$ dan nilai $\mathrm{p}=0.000$, artinya semakin tinggi perceived organizational support maka semakin rendah turnover intention, dan sebaliknya semakin rendah perceived organizational support maka semakin tinggi turnover intention.

Tabel 4. Sumbangan Efektif

\begin{tabular}{lllll}
\hline Model & $\mathbf{R}$ & R Square & Adjusted $\mathbf{R}$ Square & Std. Error of the Estimate \\
\hline $\mathbf{1}$ & $.509^{\mathrm{a}}$ & .259 & .253 & 10,138 \\
\hline \multicolumn{5}{c}{ Sumber : Analisis data Product Moment SPSS 19 for windows }
\end{tabular}


Berdasarkan tabel 4 Sumbangan Efektif di atas, dapat disimpulkan dalam penelitian ini diperoleh koefisien determinasi $\mathrm{R}$ Square $\left(\mathrm{R}^{2}\right)$ sebesar 0,259. Berdasarkan hasil tersebut, dapat disimpulkan bahwa sumbangan 25,9\% (persen) perceived organizational support mempengaruhi turnover intention dan selebihnya 74,1\% (persen) dipengaruhi oleh faktor lain, seperti komitmen organisasi, kepuasan kerja, kepuasan gaji, stres kerja, job demand, job insecurity dan konflik peran ganda.

Dengan demikian, dapat diambil kesimpulan bahwa semakin tinggi tingkat perceived organizational support yang dirasakan maka semakin rendah tingkat turnover intention. Sebaliknya semakin rendah tingkat perceived organizational support yang dirasakan maka semakin tinggi tingkat turnover intention.

\section{SIMPULAN}

Berdasarkan hasil-hasil yang telah diperoleh dalam penelitian ini, maka dapat disimpulkan sebagai berikut: Ada hubungan negatif antara perceived organizational support dengan turnover intention pada karyawan di PT. Matahari Department Store dengan korelasi Product Moment (r) sebesar -0.509 dengan p sebesar 0,000 ( $p<0,05)$. Artinya semakin tinggi perceived organizational support, maka semakin rendah turnover intention, dan sebaliknya jika semakin rendah perceived organizational support, maka semakin tinggi turnover intention.

Hasil penelitian ini membuktikan bahwa sumbangan yang diberikan variabel perceived organizational support terhadap variabel turnover intention adalah sebesar 25,9 \% (persen), selebihnya 74,1 \% (persen) dipengaruhi oleh faktor lain yang tidak diteliti, seperti komitmen organisasi, kohesivitas kelompok, kepuasan kerja, kepuasan gaji, stres kerja, job insecurity, job demand dan konflik peran ganda.

\section{UCAPAN TERIMAKASIH}

Penulis mengucapkan terima kasih kepada PT. Matahari Department Store 261 Medan yang telah mengijinkan untuk melaksanakan penelitian, dan kepada dosen pembimbing yang telah memberikan pengetahuan, saran dan arahan dalam menyelesaikan penelitian ini. 


\section{DAFTAR PUSTAKA}

Ajzen, I. (2005). Attitudes, Personality and Behavior. London: Open University Press. Diakses dari https://books.google.co.id/books?id=dmJ9EGEy0ZYC\&pg=PA117\&dq=Ajzen+(2005),+dalam+Theor $\mathrm{y}+$ of+Planned+Behavior+turnover+intention\&hl=id\&sa=X\&ved=0ahUKEwjO_fmw5vbaAhWCj5QKH W3ND_gQ6AEIKDAA\#v=onepage\&q=Ajzen\%20(2005)\%2C\%20dalam\%20Theory\%20of\%20Plann ed\%20Behavior\%20turnover\%20intention\&f=false.

Anshori, A. K., Wangi, E. N. (2017). Pengaruh Perceived Organizational Support dan Komitmen Organisasi terhadap Intensi Turnover. Psikologi Universitas Islam Bandung. Vol.3, No.2, pp. 1067-1074. Diakses dari

https://www.google.com/search?q=.+Pengaruh+Perceived+organizational+Support+dan+Komitme n+organisasi+terhadap+Intensi+Turnover\&oq=.+Pengaruh+Perceived+organizational+Support+da $\mathrm{n}+$ Komitmen+organisasi+terhadap+Intensi+Turnover\&aqs=chrome..69i57j69i59l2.12552j0j7\&sour ceid $=$ chrome\&ie $=$ UTF-8.

Arikunto, S. (2010). Prosedur Penelitian Suatu Pendekatan Praktik. Jakarta: Rineka Cipta.

Azwar, S. (2014). Reliabilitas dan Validitas. Yogyakarta: Pustaka Pelajar.

Azwar, S. (2014). Penyusunan Skala Psikologi. Yogyakarta: Pustaka Pelajar.

Bitha, S., Ardana, I. K. (2017). Pengaruh Keterikatan Kerja, Persepsi Dukungan Organisasional dan Komitmen Organisasi terhadap Turnover Intetnion Karyawan Muji Motor. E-jurnal Mnajemen Unud. Vol. 6, No. 2. Diakses dari https://media.neliti.com/media/publications/241746-pengaruhketerikatan-kerja-persepsi-duku-b70ee80f.pdf.

Burke, R. J., Cooper, C. L. (2009). The Peak Performing Organization. New York: British library. Diakses dari https://books.google.co.id/books?id=HYR9AgAAQBAJ\&pg=PA204\&dq=perceived+organizational+s upport+Fairness,+Supervisory+Support,+Organizational+Reward+and+Job+Conditions+Rhoades+d

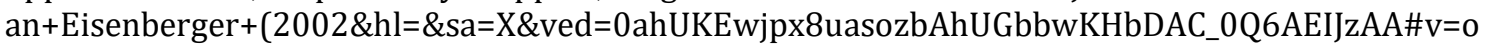
nepage $\& \mathrm{q} \& \mathrm{f}=$ false.

Hober, B. (2017). Firm Internal Innovation Contests . Germany : Springer Gabler, Diakses dari https://books.google.co.id/books?id=5MVCDgAAQBAJ\&pg=PA53\&dq=theory+of+perceived+organi zational+support+is\&hl=id\&sa=X\&ved=0ahUKEwjp8LXR1vbaAhXDW5QKHYkmCYcQ6AEISjAF\#v=0 nepage\&q=theory $\% 20$ of $\% 20$ perceived $\% 20$ organizational $\% 20$ support $\% 20 \mathrm{is} \& \mathrm{f}=$ false.

Ismaidar, H. (2012). Manajemen Unit Kerja. Sleman : CV. Budi utama. Diakses dari https://books.google.co.id/books?id=4pdKCAAAQBAJ\&pg=PA133\&dq=persepsi+dukungan+organis asi\&hl=id\&sa=X\&ved=0ahUKEwier6Cu6vfaAhXIKJQKHe5LCQcQ6AEIKDAA\#v=onepage\&q=persepsi $\% 20$ dukungan\%20organisasi\&f=false.

Jansen, P. G. W. \& Rodt, G. (2015). Conseptualising and Measuring Work Identity. South-

African Perspectives and Findings. New York London: Springer Dordrescht Heidelberg. Diakses dari https://books.google.co.id/books?id=mY_HBAAAQBAJ\&pg=PA126\&dq=definition+of++intention+tu rnover\&hl=en\&sa=X\&ved=0ahUKEwido6v45dXJAhVFjJQKHZ4TBdQQ6AEIOTAH\#v=onepage\&q=def inition\%20of\%20\%20intention\%20turnover\&f=false.

Kevin, B. (2017). Pengaruh Leadership Capability terhadap Turnover Intention melalui Job Satisfactiondi PT. Rajawali Nusindo. Agora. Vol. 5, No. 1. Diakses dari https://media.neliti.com/media/publications/136045-ID-none.pdf.

Kim, T., Adeli, H., Cho, H., Gervasi, O., Yau, S. S., Kang, B., \& Villalba, J.G. (2011). Grid and Distributed Computing. London New York: Springer Heidelberg Dordrecht. Diakses dari https://books.google.co.id/books?id=krWrCAAAQBAJ\&pg=PA303\&dq=definition+of+turnover+inte ntion\&hl=en\&sa=X\&redir_esc=y\#v=onepage\&q=definition $\% 20$ of $\% 20$ turnover $\% 20$ intention\&f=fals e.

Nanda, N. N. K., Utama, W. M. (2015). Pengaruh Konflik Kerja Keluarga Dan Kepuasan Kerja Terhadap Tingkat Turnover Intention Karyawan Pada Restoran Pizza Hut Mall Bali Galeria. EJurnal Manajemen Unud, Nol.4 ,No. $\quad 9 . \quad$ Diakses https://ojs.unud.ac.id/index.php/Manajemen/article/view/12879/10299.

Priyatno, D. (2010). Teknik Mudah dan Cepat Melakukan Analisis Data Penelitian dengan SPSS. Yogyakarta : Gaya Media.

Radzi, S. M., Sumarjan, N., Chik, C. T., Zahari, M. S. M., Mohi, Z., Bakthiar, M. S. F. \& Anuar F. I. (2015). Theory 
and Practice in Hosipitality and Tourism Research. Taylor \& Francis Group, London, UK. Diakses dari https://books.google.co.id/books?id=RisBAAAQBAJ\&printsec=frontcover\&dq=theory+and+practice + in +hospitality+and+tourism\&hl=id\&sa=X\&redir_esc=y\#v=onepage\&q=theory\%20and\%20practice $\% 20$ in \%20hospitality\%20and\%20tourism\&f=false.

Putra, P. D. S. S., Suana, W. (2016). Pengaruh Percived Organizational Support dan Komitmen

Organisasi terhadap Turnover Intention Karyawan. E-jurnal Manajemen Unud. Vol. 5, No. 10. Diakses dari https://ojs.unud.ac.id/index.php/Manajemen/article/view/22380/15744.

Rahmasari, A., Iemalia, M. S., Widyaningrum, M. E. (2017). Pengaruh Kepuasan Kerja, Kompensasi Dan

Motivasi Terhadap Turnover Intention Pada Karyawan Bagian Sales Di PT. Gading Murni Surabay. Jurnal Manajemen $\quad$ Branchmark. Vol 3 Issue $3 . \quad$ Diakses https://www.google.com/search?client=firefox-b

$\mathrm{d} \& \mathrm{q}=$ jurnal+pengaruh+Motivasi+kerja+terhadap+turnover+intetnion $\% 2 \mathrm{C}+$ Rahmasari+\%282017\% $29+$.

Ridlo, I. A. (2012). Turnover Karyawan Kajian Literatur. Surabaya : Phmovement publication. Diases dari https://www.scribd.com/doc/78478535/Turn-Over-Karyawan-Kajian Literatur.

Saefullah, K., Sule, E. T. (2005). Pengantar Manajemen. Jakarta : Kencana Prenada Media Group.

Sugiati, T., Khaidir, M. 2016. Pengaruh Stres Kerja, Kompensasi Dan Kepuasan Kerja Terhadap

Turnover Intention Studi Pada Karyawan Kontrak PT. Gagah Satria Manunggal Banjarmasi. Jurnal Wawasan Manajemen, Vol. 4, Nomor $\quad 3 . \quad$ Diakses dari https://www.google.com/search?safe=strict\&client=firefox-b-d\&ei=Z2xOXuaCL_Sb4

EPgbuigAc\&q=+pengaruh+kompensasi+terhadap+turnover+intention+sugiati+2016\&oq=+pengaruh+kom pensasi+terhadap+turnover+intention+sugiati+2016\&gs_l=psyab.3...4715.518093..518980...1.0..2.4 47.11683.0j28j23j3j1...2..11....1..gwswiz......0i7i30j0i8i67j0i8i30j0i333i395j0i8i7i30j0i7i5i30j0i22i 30j0i22i30i395j0j0i333j33i160i395.Jycier7qm2k\&ved=0ahUKEwim0omtguDnAhX0zTgGHYGdCHA Q4dUDCAo\&uact=5.

Sulistyawati,A. I., Rahmawati, S. A. \& Lestari, H. S. (2014). Pengaruh Komitmen Profesional, Komitmen Organisasional, Konflik Peran, Ketidakjelasan Peran Terhadap Kepuasan Kerja dan Keinginan Berpindah Kerja Auditor. Jurnal Ekonomi dan Bisnis. Vol. 55, No.5. Diakses dari http://repository.uksw.edu/bitstream/123456789/5915/2/PROS_Ardiani\%20Ika\%20S,\%20\%20S iti\%20Annisah\%20R,\%20Herwening\%20SL_Pengaruh\%20Komitmen\%20Profesional_\%20fulltext. pdf.

Suryani, H. (2016). Metode Riset Kuantitatif. Jakarta : Prenada Media Group. Diakses dari https://books.google.co.id/books?id=YHADwAAQBAJ\&pg=PA127\&dq=dimensi+dukungan+organis asi\&hl=id\&sa=X\&ved=0ahUKEwj03PHkrYPbAhWGF5QKHbYADhUQ6AEINjAD\#v=onepage\&q=dime nsi\%20dukungan\%20 organisasi\&f=false.

Susilo, H., Hakam, M. S., \& Sari, N. R. (2015). Pengaruh Kepuasan Kerja terhadap Turnover Intention ( Study pada AJB Bumiputra 1912 Kantor Wilayah Jatim II/Malang). Jurnal Administrasi Bisnis. Vol. 27 No. 1. Diakses

dari https://www.google.com/search?q=Pengaruh+Kepuasan+Kerja+terhadap+Turnover+Intention+(+ Study+pada+AJB+Bumiputra+1912+Kantor+Wilayah+Jatim+II\%2FMalang)\%5C\&oq=Pengaruh+Ke puasan+Kerja+terhadap+Turnover+Intention+(+Study+pada+AJB+Bumiputra+1912+Kantor+Wilay ah+Jatim+II\%2FMalang)\%5C\&aqs=chrome..69i57.1627j0j7\&sourceid=chrome\&ie=UTF-8.

Wong, W. (2012). Men(G)Akali Pikiran Cara Cerdas Negosiasi, Melobi, Memengaruhi, \& Memprovokasi Orang Lain-cet.1. Jakarta: Visimedia. Diakses dari https://books.google.co.id/books?id=coT2AwAAQBAJ\&pg=PA84\&dq=intensi+adalah\&hl=en\&sa=X \&redir_esc=y\#v=onepage \&q=intensi $\% 20$ adalah $\& \mathrm{f}=$ false. 